Figure 1.

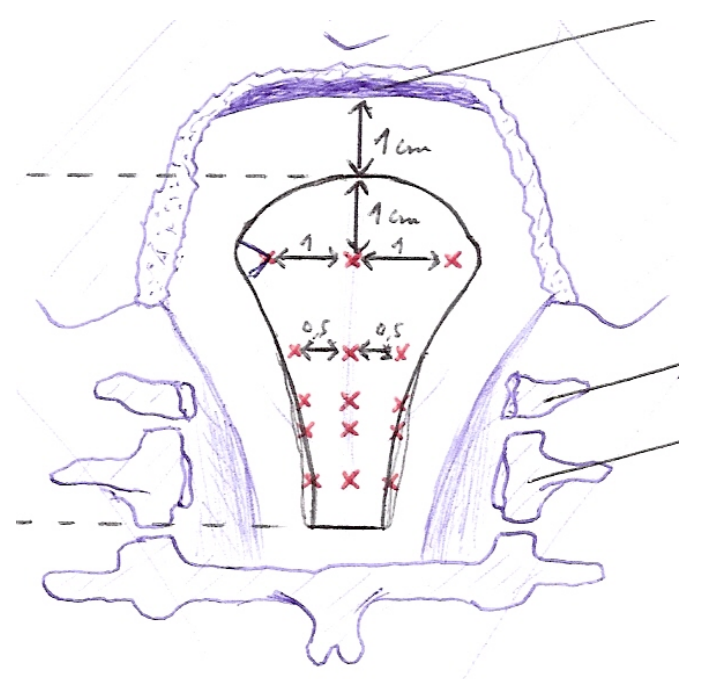

Figure 2.

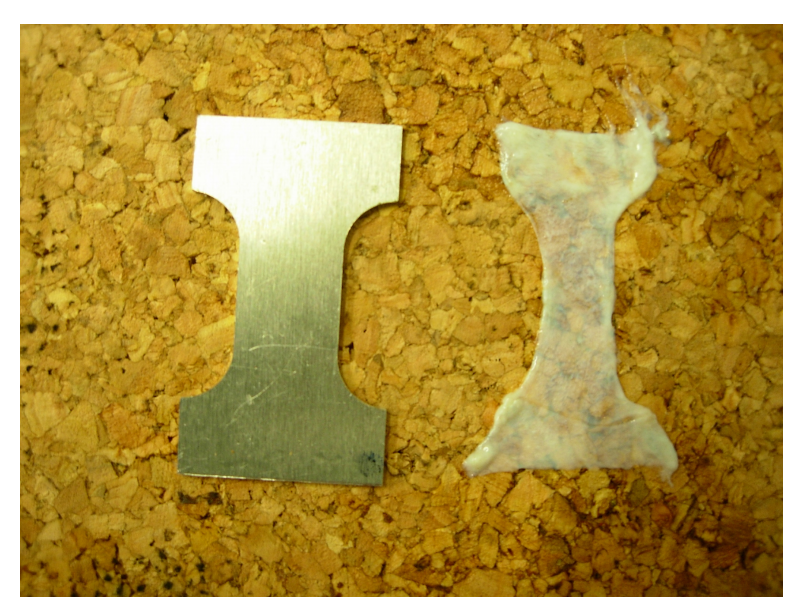


Figure 3.

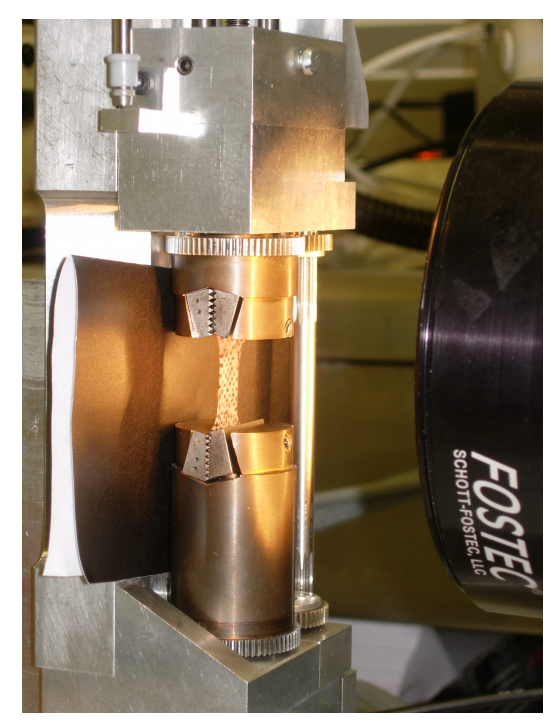

Figure 4 a)

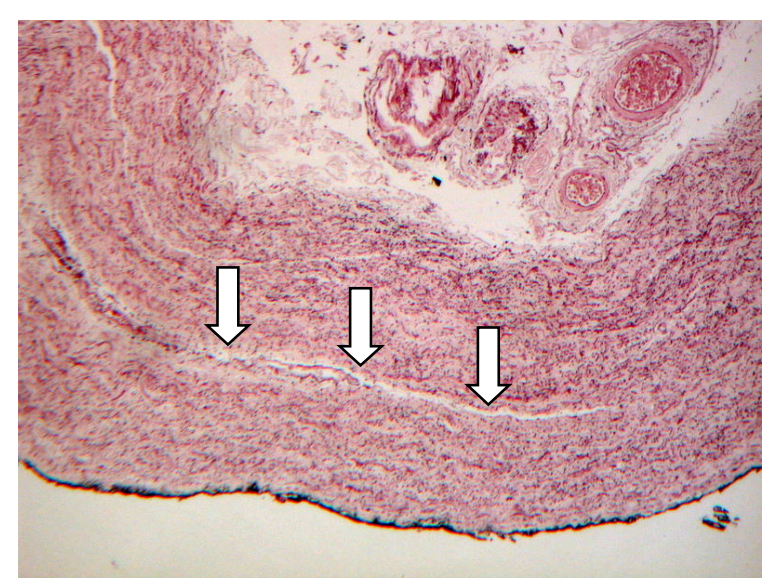

b)

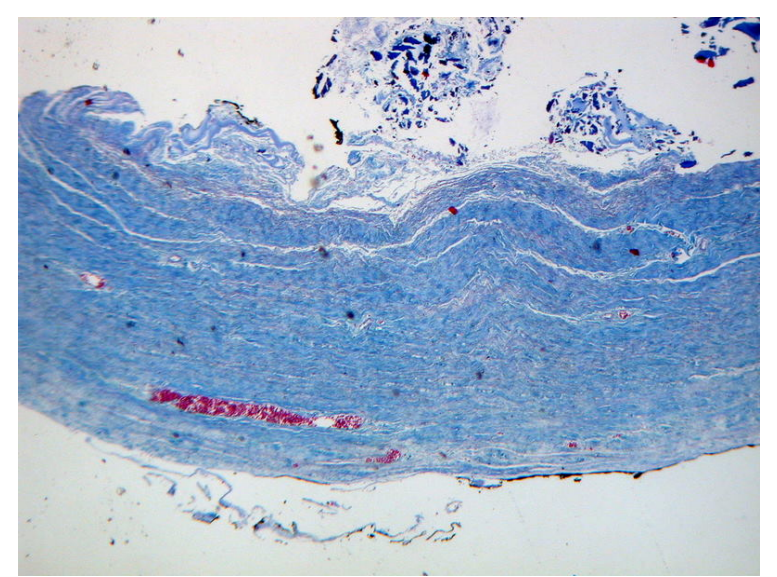




\section{Chauvet 3}

Figure 5.
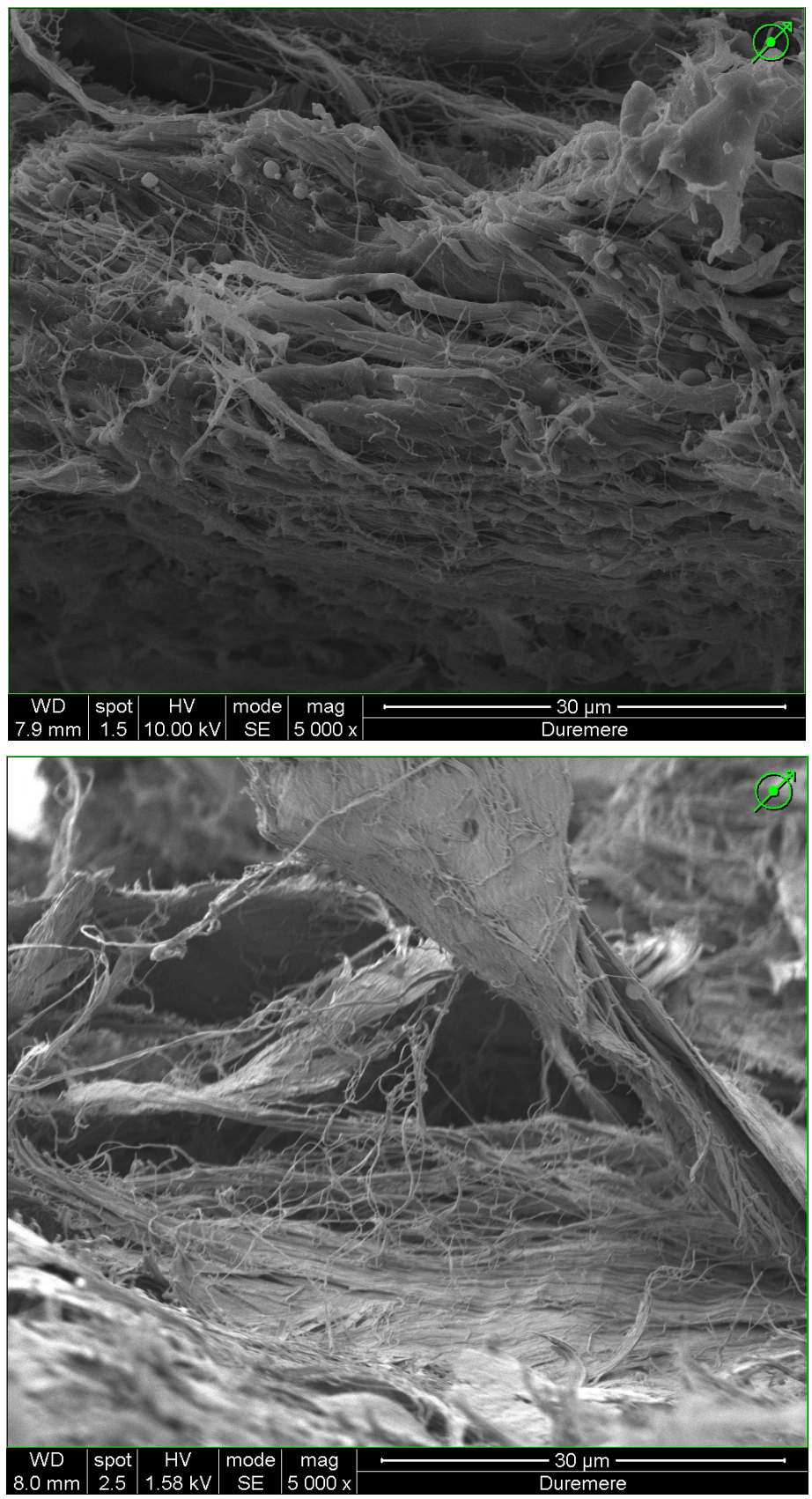
Figure 6.

Courbe Paire 1 \& 2

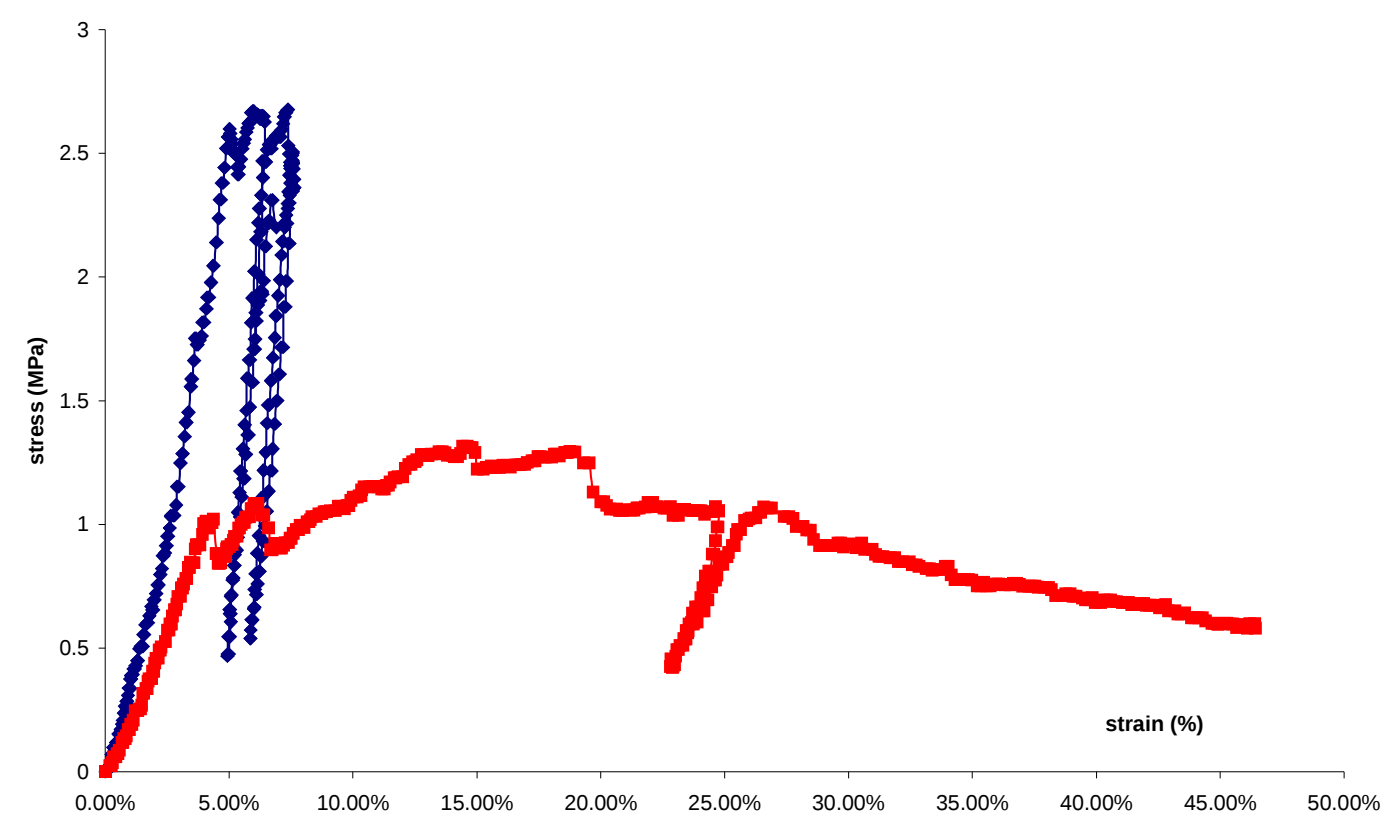

Figure 7.

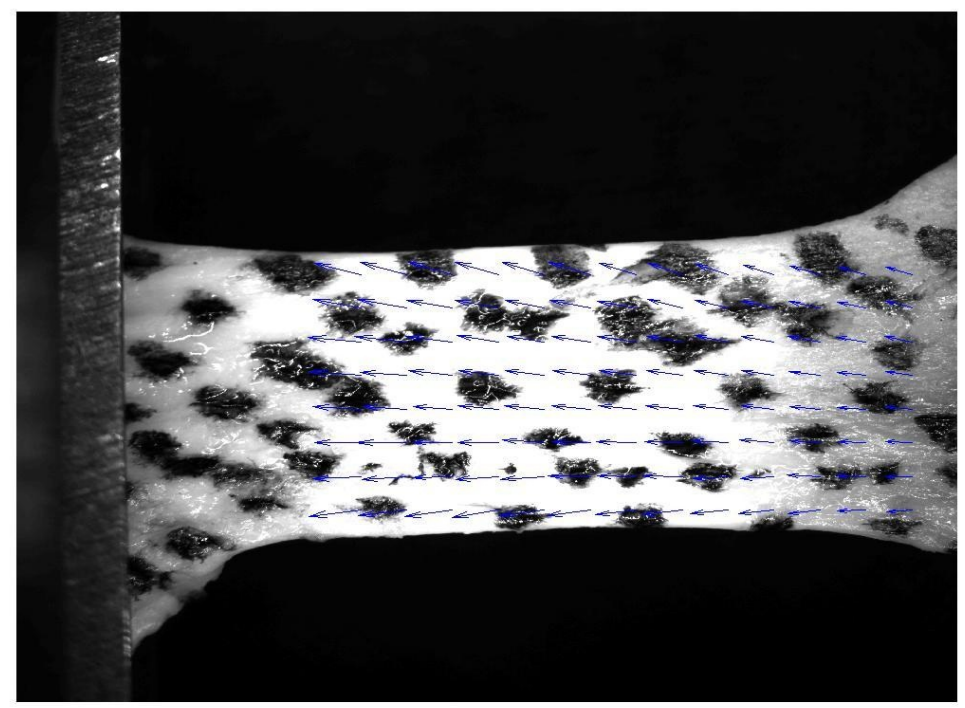


Figure 8 a)

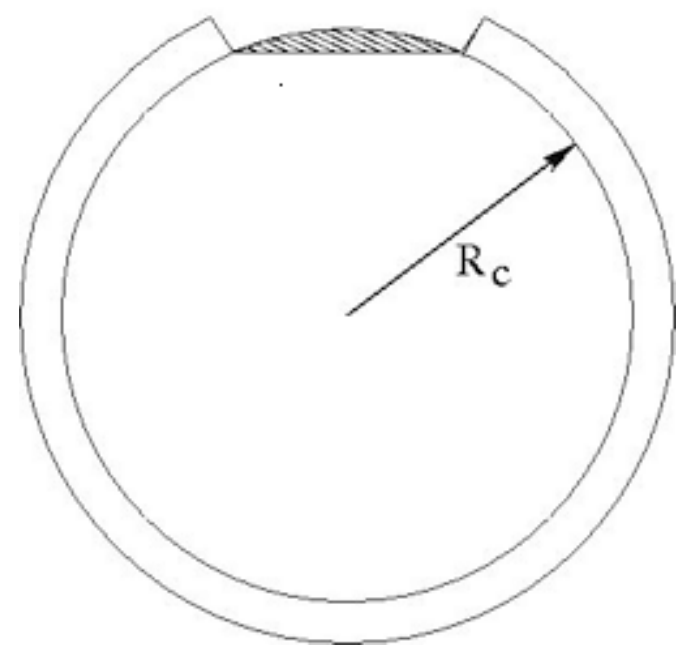

b)

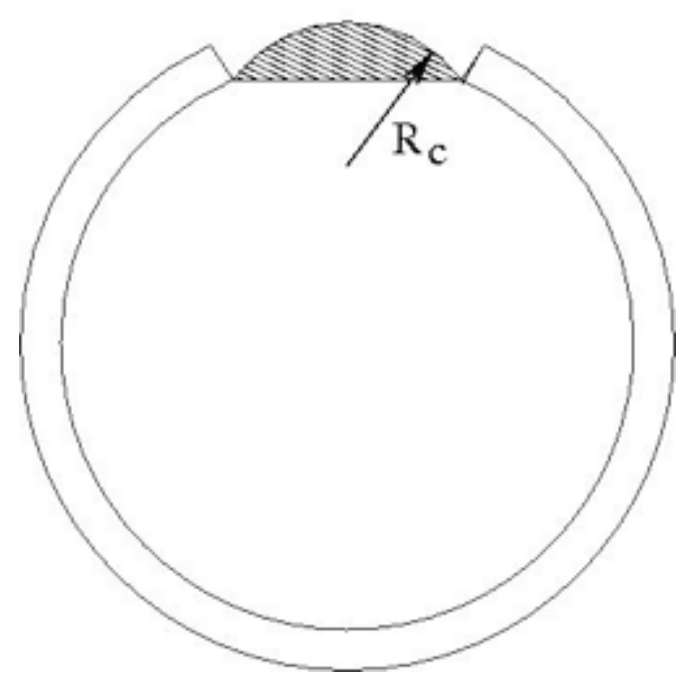

